\title{
Correction: Correlates of adherence in a home-based, self-managed exercise program tailored to wheelchair users with spinal cord injury
}

Jereme D. Wilroy $(\mathbb{D} \cdot$ Byron Lai - Ganisher Davlyatov 1 - Tapan Mehta $\cdot$ Mohanraj Thirumalai $\cdot$ James H. Rimmer

Published online: 27 July 2020

(c) International Spinal Cord Society 2020

Correction to: Spinal Cord

https://doi.org/10.1038/s41393-020-0497-4

Published online 15 June 2020
Following publication of this article, the authors noticed that the wrong Supplementary File was published. The results spreadsheet was inadvertently published in place of the complete de-identified data file. The Supplementary File has now been replaced. 